\title{
INTERVIEW WITH PEDRO PAULO ABREU FUNARI: THE LIFE PATH OF A BRAZILIAN CLASSICIST
}

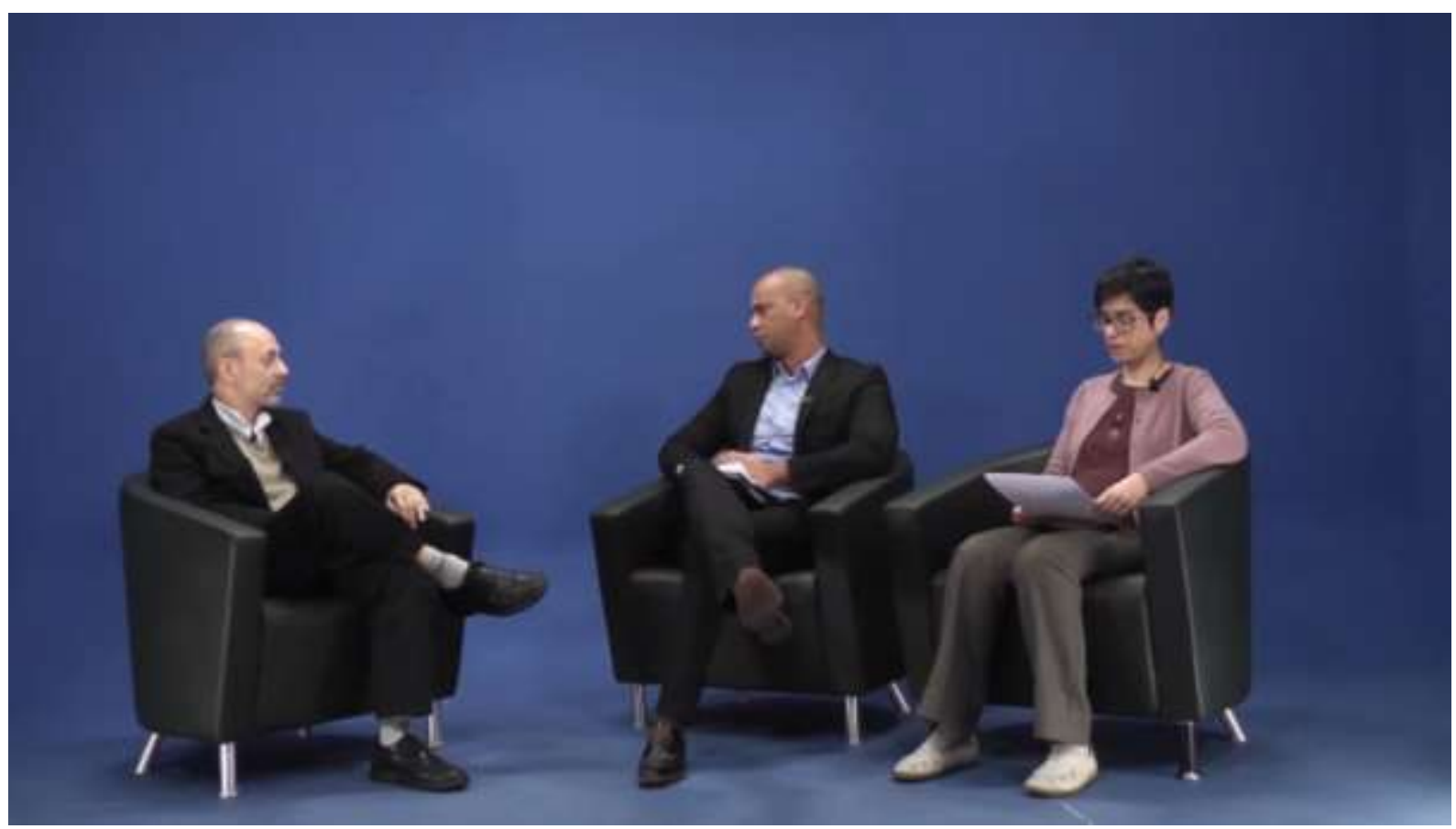

Figure 1. Interview at the UNIFESP studio in August 16, 2017: Professor Pedro Paulo Abreu Funari (UNICAMP) to the left; Prof. Glaydson José da Silva (UNIFESP) to the center; and Prof. Renata Senna Garraffoni (UFPR) to the right.

hyperlink to interview: https://www.youtube.com/watch?v=oZd-WVO7JTM

Heródoto (Glaydson José da Silva): My name is Glaydson José da Silva. I am a lecturer of Ancient History at the History Department at the Federal University of São Paulo (UNIFESP), and a co-editor of Heródoto. In this issue of our journal, we are honored to interview Pedro Paulo Abreu Funari, Full Professor of Ancient History at the University of Campinas (UNICAMP). Professor Funari, thank you very much for being with us.

In addition to myself, this interview will be conducted by Renata Senna Garraffoni, Professor of Ancient History at the Department of History at the Federal University of Paraná (UFPR). Professor Garraffoni, thank you very much for your presence. ${ }^{1}$

I begin by inviting our interviewee for a moment of self-reflection. Professor

${ }^{1}$ Interview transcribed by Erik de Lima Correia, Jemima Novaes Siqueira, and Kelly Freire Delmondes, and proofread by Gilberto da Silva Francisco, Assistant Professor at UNIFESP. 
Funari, you have now a long trajectory in the areas of Ancient Studies and Archaeology of the ancient world. Can you please tell us about the personal and professional choices that led you to tread this path in the area of Ancient Studies?

Pedro Paulo Abreu Funari: First of all, I would like to thank you, Prof. Silva and Prof. Garraffoni, for this opportunity, and to congratulate UNIFESP and the journal Heródoto for this initiative.

Well, I think that often - and also in my case -, people are led by their circumstances. This is what happened to me. Since high school, I had an interest in Ancient Philosophy, and later, when it was not possible to study in this area, I decided to study History. In History, I was interested in theory; but it was recommended to me that I should follow other paths, so I ended up, due to particular circumstances, studying Ancient History. And in Ancient History, I moved on to Classical Archaeology. It was a result, so to speak, of some particularities, or circumstances.

Anyway, in my opinion, a background issue raised by this question is: why the interest in Antiquity? I think this is strongly linked to the previous emergence of a personal imagery. It includes my own, individual imagery, but also the imagery in the reality of Brazilians, with books such as C.W. Ceram's Gods, graves and scholars, ${ }^{2}$ a work written after World War II by a German author, which was quite disseminated in Brazil back then, and which filled its readers with wonder, with its accounts of archaeologists who discovered the ancient world, Troy and the Mediterranean. So I'd say it was a combination of factors. But the one thing I like calling attention to is the fact that opportunities started to appear in my way, especially in connection with the archaeology of the Roman world, and I seized them. Further on, other opportunities led me to other themes - some of them are quite distant from the previous ones. But, they were also, in turn, a result of particular circumstances.

Heródoto (Renata Senna Garraffoni): Professor Funari, from an academic standpoint, which authors and works most strongly influenced your choices?

Funari: Well, I think it would be good to divide things into different periods of time. Because in my undergraduate years, the Marxist literature had a strong influence on me: for instance, Louis Althusser, who was one of the great names back in the 1970s. Specifically in regard to Antiquity, some French authors, such as Charles Parain and Monique Clavel-Lévêque, and Russian

2 C. Walter Ceram. Deuses, Túmulos e Sábios. São Paulo: Melhoramentos, 1957. 
authors translated into German, such as E. M. Staerman, had a strong influence on me in that initial period - in the 1980s.

I continued my studies following the changing tides, which were also a result, by the way, of postmodernism in general. These tides led me to a wider literature and authors such as Paul Veyne, Michel Foucault and even Moses Finley, who was linked, on his turn, to a Weberian strand. I'd say this was the period of transition between the 1980s and 1990s. When I became a UNICAMP faculty member in the 1990s, I'd say that I moved toward a literally more postmodern current, with issues such as multiple identities, the theory of Foucault's ideas and diversity, and the focus on how the past is constructed in the case of the ancient world, some authors also follow this line of reasoning. I'd say this is a complex portrait, because no previous author or previous experience was ever left aside by me. I do believe this is worth mentioning.

Heródoto (Silva): Professor Funari, regarding the Greeks, the Romans and us; regarding the ancients and the moderns; and regarding the ancients and our contemporaries. What can the history of Antiquity tell us about the present? Does classical culture have something to tell us beyond the role of tradition in the history of Western thought?

Funari: Well, in this regard, I believe there are two important things. First, you mentioned tradition. I think it is indeed necessary to cover a certain repertoire, because we are talking about a culture with references to values such as democracy, or even beliefs founded upon it; for instance, Christianity, which has a lot to do with Greek philosophy. In Christianity, for instance, the Gospel of John basically begins with a Greek reflection. I think it is simply not possible to avoid tradition in this repertoire. But, beyond it - as you said, beyond the issue of this repertoire -, there is also the issue of the uses that can be made of it; which, oftentimes, are quite biased and strive at insufficiently clear aims. These uses can also enable many forms of arbitrariness and injustice.

As I see it, an important factor for the study of the linkages between this more distant past and the present is the awareness of the ways in which it was manipulated. It is not possible for us not to manipulate (manipulate, exploit...) it; but in any way, it is interesting to point out how it was appropriated by social groups and interest groups. For instance, there is a clear appropriation of Sappho, the Greek female poet, by women's liberation movements and gender movements. But it is necessary to understand the status of these things, not only as a cult to Antiquity, or a cult to Sappho; nor is it the case of 
considering only the contemporary world, for one must also bear in mind the ancient world. Another good example is the Spartacus movement in Germany in the early $20^{\text {th }}$ century, which was also directly inspired by Antiquity and, therefore, by Spartacus. So it is neither the case for studying only the ancient Spartacus, nor only the contemporary movement. Rather, it is the case of showing this dialectic contrast.

Heródoto (Garraffoni): Professor Funari, in this interview, we have mainly approached theoretical standpoints so far; but our readers may also be interested in the beginning of your studies and the selection of your themes, considering the large diversity of your publications, which range from popular Greek culture, and the Romans, to early Christianity, covering economics and issues linked to gender and sexuality. Can you tell us more about how these themes emerged in the course of your researches?

Funari: This summary you made shows that there is indeed a huge diversity of themes. Once again, this diversity is a product of two issues. The first of them is the issue of circumstances. I think that as historians, the contingencies of current circumstances are fundamental elements, because we are often led forward. I was led to certain themes by force of circumstance. For instance, I started studying graffiti and popular culture by force of circumstance, when I was first invited to talk about it. I had to pay attention to it, and from then on, I developed researches on this theme. The same thing, I'd say, applies to gender. I joined UNICAMP as a faculty member and inserted myself in the gender field, i.e. in the field of gender relations. So this brought me a set of concerns I originally did not have.

Other themes, in turn, were linked to issues of my personal background: for instance, Christianity and religiosity. They were connected to readings not only of the Bible, but also of some other religious texts - such as the works of Ernest Renan, a 19th century author who was a great scholar of religious phenomena and nationalism -, which I used to read as a university student. I started reading them without an academic interest, which, on its turn, only emerged much later. I think this is what serves as an inspiration, or may serve as an inspiration for our young students, considering that we must pursue specialized studies quite precociously in the universities, and it is important that, beyond it, people can always be open to other paths.

Heródoto (Silva): From the standpoint of the training and intellectual production of Antiquity historians, what limits and possibilities do you see for 
these scholars in Brazil and in Europe?

Funari: Well, in Brazil, I think the current situation is quite favorable. Some decades ago, we had difficulties in terms of access to documents and bibliographical references, and even in terms of traveling to visit and work at archaeological sites. Nowadays, many of the necessary documents are available to us; we have access to practically all journals, and the possibilities in terms of traveling improved a lot. So, for students willing to develop themselves in this area, there is a quite new situation in Brazil, as well as in other regions of the so-called New World, including the United States, Australia and other places outside Europe.

Moreover, there is a largely discussed 'classics crisis' issue, particularly in Europe, as a result of the decrease in the number of Latin, Greek or Classical Archaeology departments there. But I do think all this is largely a product of the circumstances, and not of permanent elements. I think that, contrary to the current trends, these fields will regain their ground as important focal areas of study, because I see the interest of countries such as Japan or China, which are countries from other traditions, but are truly interested in Western culture and, in particular, in Antiquity. So I am an optimist.

Heródoto (Silva): One may say that the access and current possibilities for young scholars are much better nowadays. We have now practically the entire collection of texts published in Latin-English, Latin-French, or Greek-English and Greek-French, in addition to the corpus of images and epigraphic collections. So, for young scholars nowadays, access to these resources at the virtual space is much better and broader than before.

Funari: Furthermore, in order to learn a language nowadays, one may even take courses via Skype. In the past, it was necessary to have a teacher physically. So, at the heart of the matter, of course this is always something contradictory, since technological developments spare the workforce and produce unemployment. But this does not change the fact that access to information and to new possibilities is increasing on a daily basis; even though robots are working for human beings, there remain other activities, such as Skype lessons.

Heródoto (Garraffoni): In this context, do you see this global and Brazilian perspective as a favorable setting for those who are now entering the universities, and think about becoming experts in Ancient Studies? 
Funari: In this regard, I think we are entering a difficult area, since we live amidst political, social and economic circumstances that depend neither on us, nor on the students. Thus, it is difficult to evaluate these general circumstances. Yet, from a strictly academic or professional standpoint, I think the current perspectives are quite good, for the following reasons. First, because there is a higher education market out there. All around Brazil, universities are in need for specialists, and we also have the school system with its secondary and basic levels, which since decades have been increasingly emphasized.

For a country to attain a conscious citizenry and economic development, its youth must be well educated. It is necessary to count with good teachers, who know world history by and large, and who are also knowledgeable about Antiquity. There are many experiences of the use of Greek texts, Greek tragedies or Latin comedies in secondary school - even in elementary school, sometimes. Some schools in São Paulo are now experienced in teaching Greek, at the initiative of Professor Paula Correia from the University of São Paulo (USP), and some public schools are now offering Greek as an elective discipline. So, in short, I think there is a quite large field, if only people opened themselves to these possibilities.

Heródoto (Silva): In a general way, we are noticing that for young students in the fields of Ancient History, and Antiquity, there is now an entire universe of new possibilities that were not known before. But they do not displace the need for personal experiences, both during their undergraduate training and subsequently, in foreign institutions - as was the case for many of your students.

Funari: I think this is part of what we were just talking about, i.e., the insertion of Brazilian scientists - in particular, experts on the ancient world - in the international context. 30 years ago, it was much more difficult for Brazilian researchers to insert themselves internationally. Only a few scholars had both the ability and the conditions, considering the circumstances, to find professional placement abroad. Nowadays, such insertion is much more frequent, both in the archaeological field work and in partnerships with international professors - either as a part or the entirety of a student's training period. So I believe this creates an important anthropological aspect, namely experience in other academic systems.

Brazil is a quite large country, and we relate to this country as if it were a universe, assuming that we only need to know one language, and that we can position ourselves in such a large country and find our opportunities inside it. 
However, when we go abroad, we enrich ourselves; in Argentina or Spain, France, England, the United States, Australia, and so on. We come into contact with other types of observations about the ancient world, and we perceive that we can make truly original contributions, due to the fact that we do not come from one tradition only. In many countries with a long-standing tradition, i.e. a tradition of centuries in a specific area, people end up following their own tradition from a region, or even from a university. So, by virtue of this distinction, we are faced with this possibility.

Heródoto (Silva): I'd like ask you a question linked to a reflection more directly under the scope of Heródoto (the relations between the Classical world and its Afro-Asian connections). A long-standing historiographical tradition has contemplated a myriad - that is, an extremely wide range - of themes and studies on Antiquity, particularly since the late 19th century. But this same historiographical tradition still contemplates non-hierarchical relations between East and West superficially. In this regard, for instance, Martin Bernal's work $^{3}$ is quite illustrative, since he shows less hierarchic evidences in the relations between these different traditions. Can you please make comments on this topic?

Funari: I think that in the case of Martin Bernal, there were many controversies, which you know well; 4 because he was an expert in China writing about another theme. But beyond this controversy, I think that the fundamental issue is the one you mentioned, namely openness to the realm of Antiquity toward the East, toward Africa and even the Far East. In the past, these relations were particularly forgotten, for instance in the specific case of Egypt, which Martin Bernal explores quite well - the Egyptian origins and several cultural ties. And even with the East, it is impossible to extricate Antiquity from a specific point in time on, from India, for instance. And no one thinks about India when speaking about Hellenistic culture; the culture of the long period that started in the century immediately before Christ and extends itself to the entire Roman period. And even Christianity, for instance,

3 Martin Bernal. Black Athena: The Afro-Asiatic Roots of Classical Civilization: The Fabrication of Ancient Greece, 1785-1985. Vol. 1. New Brunswick; New Jersey: Rutgers University Press, 1987; Martin Bernal. Black Athena: The Afroasiatic Roots of Classical Civilization. Vol. 2. New Brunswick; New Jersey: Rutgers University Press, 1991; Martin Bernal. Black Athena: The Afroasiatic Roots of Classical Civilization: The Linguistic Evidence. Vol. 3. New Brunswick; New Jersey: Rutgers University Press, 2006.

${ }^{4}$ For this discussion, see, for instance, Mary R. Lefkowitz; Guy MacLean Rogers (eds.). Black Athena Revisited. Chapel Hill: University of North Carolina Press, 1996; Martin Bernal; David Chioni Moore (ed.). Black Athena Writes Back: Martin Bernal Responds to His Critics. Durham; London: Duke University Press, 2001. 
in the Gospel of John, cannot be possibly extricated from Greek philosophy, which, in turn, cannot be extricated from the East.

I think that the background issue is: Classical Studies have been frequently used from a reactionary standpoint, to defend the established order - the relations of hierarchy and domination over colonial populations. Such uses intensely marked them as an academic discipline. One finds some very conservative works, including theory books that appear to be very attractive, but in fact are quite conservative: for instance, Werner Jaeger's Paideia, 5 which depicts a much idealized view and became a right-wing instrument. However, to conclude, I'd say that Antiquity can also serve an opposite aim, i.e., of illuminating certain aspects and then reaching beyond, as you mentioned, toward the East, and toward Africa, thus overcoming the false idea of an autochthonous Western culture - a thing that does not exist.

Heródoto (Silva): Another extremely important aspect of Martin Bernal's work, as I see it, is that it calls attention to how the ancients saw their own history, and how the Greeks saw their history as something largely influenced by the cultures of Northern Africa, and by Egyptian culture; therefore, he calls attention to an aspect that is commonly forgotten and neglected in historiographical studies. This aspect is newly addressed in the context of his work, which has such a thought-provoking title: Black Athena: The Afroasiatic roots of classical civilization. This title, by itself, is a huge provocation.

Funari: Exactly. You put it very well. The ancient works themselves are frequently read with notions that have nothing to do with the ancient peoples. Well, we're modern. It takes us back to the issue of the contemporary / ancient relation. It is impossible to gain access to Antiquity without going through subsequent moments, especially in the $19^{\text {th }}$ and $20^{\text {th }}$ centuries. It means that the interpretation of the past has been utterly biased. A classic example we may point at is the case of sexuality. The ancients were different from us. In any historical period, people were different. As to Antiquity, this means that some completely anachronistic interpretations have been made in the recent past. In regard to sexuality, a long time elapsed before one could approach this theme and imagine that it could be discussed as it is nowadays. For a long time, this was a dormant theme, i.e. a theme that did not exist. To a large extent, the same is still to be done in regard to Eastern and African cultures. As you said, this concern dates back to the $19^{\text {th }}$ century, a period when many authors were dwelling on this connection with the East, and were fascinated with India and China (India, especially). Many approximations took place then, but these still

${ }^{5}$ Werner Jaeger. Paideia: a formação do homem grego. São Paulo: Martins Fontes, 1994. 
continue to be minor themes in the historiography of the ancient world.

Heródoto (Garraffoni): These considerations are important so we may think more about the historians' craft. How historians are treating theory, the available documents, and, in a certain way, the forms we mobilize in the relations between the past and the present. So I believe this type of reflection is a fundamental element of Heródoto's proposal as a journal. Would you like to make any comment in this regard?

Funari: In this regard, it is necessary to say that we are fortunate to count now with a larger number of periodicals in Brazil than before, including journals about the ancient world. But the originality of Heródoto as a journal - which, I think, must be highlighted - lies precisely in its emphasis on unorthodox paths; in its endeavor to take a step beyond and reach out for this linkage between past and present, and these connections between East, West and Africa. I do think this is a great innovation, and I congratulate UNIFESP in this sense as well.

Heródoto (Silva): To conclude, I'd like to go back to what you said just a moment ago, and to ask you a last question. You just spoke about how the past is conceived - an issue that also emerged in Prof. Garraffoni's remarks. We see in our country a long-established tradition in relation to the uses of the past, which once were not understood as being part of the History of Antiquity, but are now accepted and understood under a new perspective. Such issues were approached by Brazilian historians of Antiquity working with this perspective, but they have not been approached by historians from other historiographical traditions. In this regard, can you explain more about your view of such reception, of the uses of the past, and whether there is a distinction between the reception, on the one hand, and the uses and appropriations of the past, on the other?

Funari: This is a broad theme, but I'd say, to state it briefly, that reception is a term largely used in the English language to emphasize the idea of something original, and the way it is received in the contemporary world. The contemporary world receives something coming from the ancient world. In my opinion, the notion of uses of the past, on its turn, has a slightly different nuance, since it is based on the idea that we, in the present, are using whatever came before us in order to express something. It is almost inevitable that we should do this, but it is not only a matter of reception, as in Physics, i.e. acoustics: one issues a sound, and the other person receives it in her ear. That 
is not the case. Quite the contrary, this is about a constant relation of interpretations. When we hear something, we are also interpreting it as we hear it. It is not possible simply to receive it. So it depends to some extent on what one understands by reception; if we understand it in this broader sense, then I think it is in line with the uses of the past.

Heródoto (Silva): I'd like to thank you very much, Professor Funari, for kindly accepting the invitation to be interviewed by myself and Professor Renata Senna Garraffoni, who made some questions that are in the interest of us all. Thank you indeed, Professor Garraffoni. And please accept our hearty thanks, Professor Funari. 